\title{
An apparent mutualism between Afrotropical ant species sharing the same nest
}

\author{
Thomas Parmentier $^{1,2} \cdot$ Kolo Yéo ${ }^{3} \cdot$ Wouter Dekoninck ${ }^{2} \cdot$ Tom Wenseleers $^{1}$
}

Received: 17 August 2016 / Revised: 6 January 2017 / Accepted: 24 January 2017

(C) Springer-Verlag Berlin Heidelberg 2017

\begin{abstract}
Social insects have a highly developed nestmate and species recognition system that is quite effective at keeping out unwanted intruders. Rare cases of "parabiosis," however, are known in some ants where two species apparently live peacefully alongside each other within the same nest. Here, we report on such an association between the tiny Afrotropical ant Strumigenys maynei and the large ant Platythyrea conradti. We demonstrated that both ants peacefully share the same arboreal nests in spite of the presence of clearly distinct nestmate recognition cues. Because of the large size differences, we hypothesized that each of the two species would benefit from specializing in carrying out particular tasks, in analogy to the size-related division of labor observed in species with size-polymorphic workers. In line with this theory, we found that the tiny ant S. maynei was highly efficient at nest defense against intranidal arthropods and alien ant intruders, whereas the large ant $P$. conradti was highly skilled in nest engineering. We argue that the described association is
\end{abstract}

Communicated by W. Hughes

Electronic supplementary material The online version of this article (doi:10.1007/s00265-017-2274-8) contains supplementary material, which is available to authorized users.

Thomas Parmentier

Thomas.Parmentier@bio.kuleuven.be

1 Laboratory of Socioecology and Socioevolution, KU Leuven, Naamsestraat 59, 3000 Leuven, Belgium

2 Entomology Department, Royal Belgian Institute of Natural Sciences, Vautierstraat 29, 1000 Brussels, Belgium

3 Station d'Ecologie de LAMTO, Université Nangui Abrogoua (ex Abobo Adjamé) UFR-SN, BP 28 N'Douci, Abidjan, Ivory Coast likely mutualistic, as $P$. conradti clearly benefited from the supreme defense capabilities of $S$. maynei, and that, conversely, $S$. maynei took advantage of small prey thriving in the organic nest material collected by $P$. conradti.

\section{Significance statement}

Associations between social insects are typically parasitic in nature. A few cases, however, are known of beneficial associations between social insects. Here, we report such a rare association between two Afrotropical species that share the same nest even though they lack matching colony odors. The large ant Platythyrea conradti benefited from the presence of Strumigenys maynei as this tiny, but highly aggressive, ant was much more efficient in attacking intranidal and extranidal enemies. S. maynei in turn took advantage of $P$. conradti as this ant constructs a unique nest which attracts suitable prey.

Keywords Ant guests $\cdot$ Caste $\cdot$ Nest defense $\cdot$ Polymorphism $\cdot$ Symbiosis $\cdot$ Task specialization

\section{Introduction}

Interspecific mutualisms, i.e. reciprocally beneficial relationships between different species, are ecologically widespread, important at several levels of biological organization and vital for ecosystem functioning (Herre et al. 1999). Mutualisms typically involve organisms that provide food and shelter in return for protection from predators and competitors. Corals, for example, provide shelter and food to herbivorous fish in return for protection from enemies such as seaweeds (Dixson and Hay 2012). Ant nests are safe environments with ample of food sources and are consequently targeted by many organisms (Kronauer and Pierce 2011). Most of these associates do 
not return benefits and are clearly parasitic (Kronauer and Pierce 2011; Parmentier et al. 2016). Yet, rare examples of "parabiosis" are known in which the nest is peacefully shared with another ant species (Hölldobler and Wilson 1990; Menzel and Blüthgen 2010). The most widely accepted theory is that parabiotic associations are of a mutualistic nature and are beneficial for both ant partners. For example, in a parabiotic association between two South-East Asian ants, one of the species, Crematogaster modiglianii, was shown to benefit from the presence of the stronger and more aggressive Camponotus rufifemur, whilst the latter took advantage of the pheromone trails and nest construction capabilities of $\mathrm{Cr}$. modiglianii (Menzel and Blüthgen 2010). A similar mutualistic association was also demonstrated in South American parabiotic ants (Davidson 1988; Vantaux et al. 2007). Nevertheless, Menzel et al. (2014) also reported that some parabiotic partners seemed to be exploited, without receiving any return benefits from the partner. Parabiotic ants tolerate the presence of another ant species in the same nest, even if both ant species typically raise their brood in different nest chambers. Surprisingly, such species do not show any aggression towards each other, often exploit the same food sources and may even use the same pheromone trails (Menzel and Blüthgen 2010).

Parabiosis can involve tight associations where both partners show colony-specific tolerance levels. In this case, only the partner colony is tolerated and conspecific and heterospecifc workers of other compound nests are aggressed by both partner colonies (Orivel and Dejean 1997; Emery and Tsutsui 2013). Other associations are less strict, as a partner might also tolerate other colonies of the partner (Menzel et al. 2008b). In contrast with most social insect parasites that mimic the odor of their host to get accepted, parabiotic ants succeed to associate even when they each have distinct chemical cuticular profiles (Orivel and Dejean 1997; Menzel et al. 2008a; Menzel et al. 2009). It is suggested that parabiotic ants are able to recognize the chemical profile of the partner using a learning process which leads to colony- or species-specific tolerance (Orivel and Dejean 1997). Nevertheless, there are also indications that a parabiotic lifestyle imposes selection pressures on the chemical profile, as parabiotic ants frequently possess exceptionally long-chain hydrocarbons and higher amounts of methyl-branched alkenes and alkadienes (Menzel and Schmitt 2012) or may carry cuticular compounds that are thought to appease the other partner (Menzel et al. 2013).

In the present study, we explored an apparent parabiotic association between the large Ponerinae ant Plathythyrea conradti Emery, 1899 and the tiny Myrmicinae ant Strumigenys maynei Forel, 1916 that was recently discovered in the Ivory Coast (Yéo et al. 2006). The aim of our study was threefold. First, we investigated the nature and specificity of the association by measuring the level of aggression between the two partners and analyzing whether they could discriminate conspecific and heterospecific workers of alien compound nests. Second, we carried out a chemical analysis of the cuticular hydrocarbon profiles of $P$. conradti and S. maynei of different compound nests to determine the chemical congruence between the associated ants across different nests. We then linked these chemical data with the behavioral assays and discuss these results with respect to the specificity of the ant association. Finally, we studied the potential benefits for both partners of engaging in the association. In species with size-polymorphic workers, it is well documented that workers of particular size cohorts specialize on carrying out specific tasks inside the colony, such as nest defense (Hölldobler and Wilson 1990; Tian and Zhou 2014; Parmentier et al. 2015). Analogously, we hypothesized that a similar specialization in nest defense between the two ant partners that vary greatly in size and morphology could bring distinct benefits to the association. Defense capabilities were tested for both ant partners towards intranidal intruders (myrmecophiles) and towards extranidal enemies (alien ant species).

\section{Material and methods}

\section{Study site and study organisms}

P. conradti and S. maynei (Fig. 1a) were found in a gallery forest along the Bandama river in the Lamto Ecological Reserve $\left(6^{\circ} 13^{\prime} \mathrm{N}, 5^{\circ} 01^{\prime} \mathrm{W}\right)$, Ivory Coast, in January 2016 (dry season). The distribution of S. maynei (Myrmecinae) is restricted to the forest zones of West and Central Africa and Uganda (Bolton 2000). This tiny (ca. $2.5 \mathrm{~mm}$ long) ant is often found nesting not only in rotten wood in the leaf litter layer but also in holes in trees (Bolton 2000). Most species of Strumigenys are specialized predators that capture small arthropods (Hölldobler and Wilson 1990; Bolton 1999). Colonies of $S$. maynei produce large number of workers and are headed by multiple queens (polygyne), but in some colonies, only one queen occurs (Yéo et al. 2006, pers. observations TP). P. conradti (Ponerinae) is a large (ca. $15 \mathrm{~mm}$ long) Afrotropical arboreal ant that produces relatively small colonies (max. 500 workers). The workers hunt solitarily and prey on a wide variety of arthropods that they kill using a powerful sting (Dejean 2011). They have an unusual social system with permanent wingless ("ergatoid") queens (Molet and Peeters 2006). New P. conradti colonies arise by splitting (fission), and a queen with workers subsequently disperses by walking to a new nest site (Molet and Peeters 2006). Both P. conradti and S. maynei are found in the absence of each other across their overlapping distribution in the Afrotropical region (pers. observations KY, Bolton 2000). However, Yéo et al. (2006) reported that $S$. maynei colonies were present in 9 
Fig. 1 Overview of the compound nest microcosm of Platythyrea conradti and Strumigenys maynei and some interactions. a Inhabitants of the compound nest: (1) P. conradti, (2) S. maynei, (3) Pselaphinae sp. (subtribe Batrisina), (4) Holotrochus sp. and (5) adults and nymphs of Neoasterolepisma delamarei. b Aggression between workers of $S$. maynei originating from different nests. c Aggression between workers of $P$. conradti originating from different nests. d $P$. conradti and $S$. maynei queen, workers and alate queen. . Typical compound nest with opening at a height between 1 and $2 \mathrm{~m}$ filled with organic material. The dotted line indicates the shape and depth of the nest in the hollow branch. The brown polygon represents the plug of organic material at the nest entrance

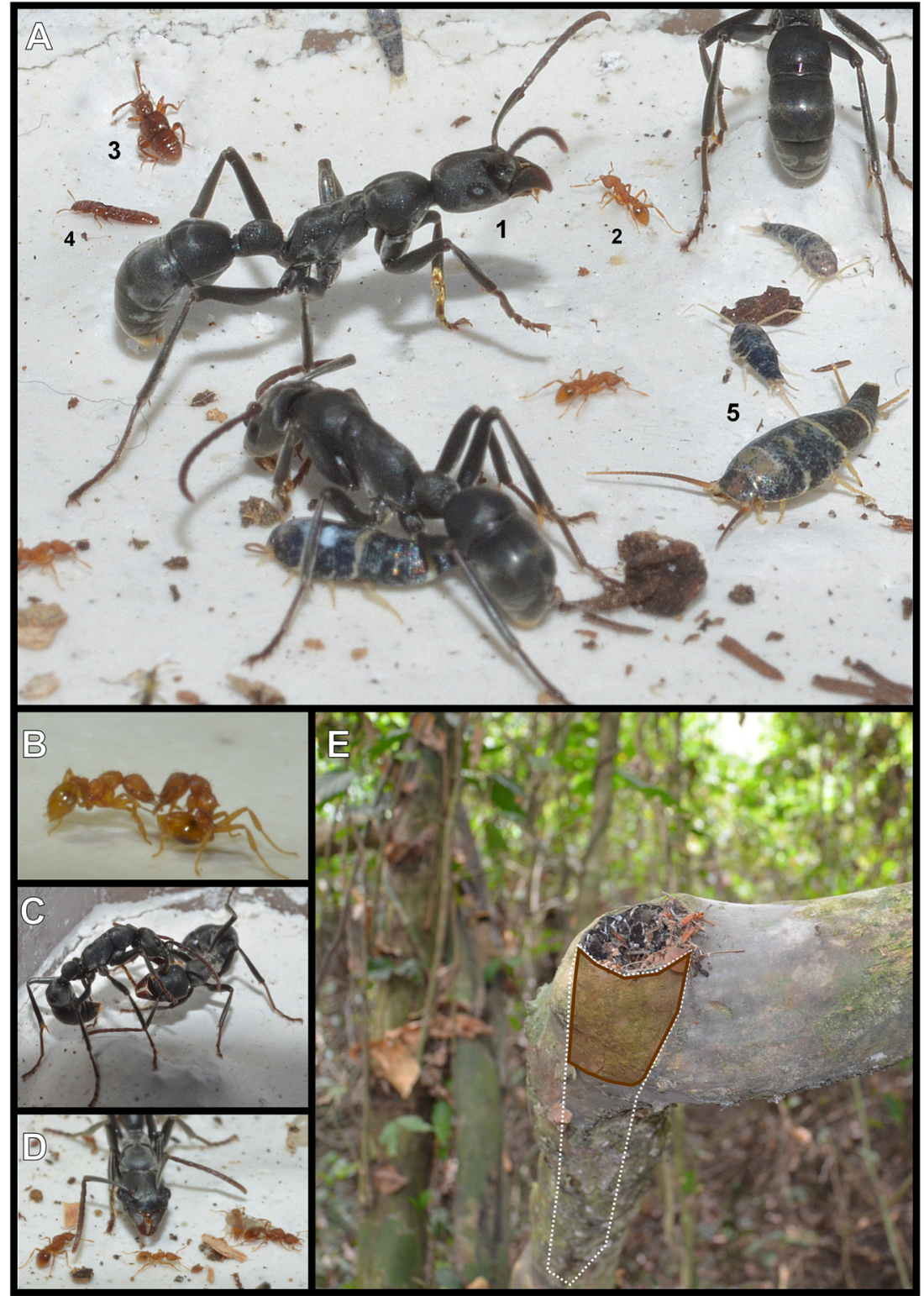

of 12 inspected P. conradti nests in Lamto. These compound nests were typically found in hollow branches of living trees (usually Pancovia bijuga, Sapindaceae) $0.5-2 \mathrm{~m}$ above ground. The openings of these branches were stuffed with organic material and faced slightly downwards or upwards (cf Fig. 1e). A number of ant-associated arthropods or myrmecophiles were also detected in the compound nests (pers. observations KY, WD).

In this study, hollow branches of ten living trees, which were characteristically filled with organic material, were opened using a machete. Organic material was collected by hand, whereas ants and myrmecophiles were aspirated. Most organic material was found near the nest entrance (plug with a length of 10-20 cm), but some debris were also found in the deeper cavities of the hollow branch. The organic material was carefully sieved in the lab to find additional ants and myrmecophiles. Ants and myrmecophiles were housed per nest in plastic 1-L containers with a bottom layer of moist plaster and organic material of the original nest. A cotton plug soaked in sugar water was provided regularly.

\section{The nature and specificity of the association}

In a series of aggression experiments, the behavior of $S$. maynei and P. conradti towards workers of the partner colony found in the same compound tree nest and towards workers of $S$. maynei and P. conradti found in other nests was tested. In all tests, the proportion of aggressive interactions (opening mandibles, biting and stinging) observed during a total of 20 interactions was scored as the dependent variable. We defined an interaction as the crossing of ant antennae with the introduced individual or one of its body parts. 
Indeed, the tiny $S$. maynei workers did not interact with the whole body of the much larger $P$. conradti workers but mainly just with their body parts (legs, antennae) that contacted the ground. Test arenas had a plaster bottom and fluon-coated walls to prevent animals from escaping. Because of the large size differences between $S$. maynei and P. conradti (Fig. 1a, d), different test arenas and number of workers were used depending on the interaction tested (overview in Table 1)

Aggression tests of $P$. conradti towards $P$. conradti workers of the same colony and alien colonies from other compound nests were done by introducing a $P$. conradti worker into an arena with one $P$. conradti worker. Both workers originated from nest $\mathrm{N}_{1}, \mathrm{~N}_{2}$ or $\mathrm{N}_{3}$, but tests were done blind to the origin of the introduced worker. Both workers were replaced in every trial.

Aggression of $P$. conradti towards co-inhabiting and alien workers of $S$. maynei was tested by introducing one $S$. maynei worker into an arena (diameter $8 \mathrm{~cm}$ ) with 10 workers of P. conradti. Workers originated from nest $\mathrm{N}_{1}$ and $\mathrm{N}_{2}$, but tests were again done blind with respect to the origin of the S. maynei worker.

Aggression of $S$. maynei towards nestmate and alien $P$. conradti workers was analyzed in an arena with a diameter of $3 \mathrm{~cm}$. Here, the behavior of three individuals of $S$. maynei towards one $P$. conradti worker was followed. These tests were done with two colonies of $S$. maynei from nests $\mathrm{N}_{1}$ and $\mathrm{N}_{3}$, and workers were replaced in every trial. $P$. conradti workers also originated from nests $\mathrm{N}_{1}$ and $\mathrm{N}_{3}$, but tests were performed blind with respect to the origin of the $P$. conradti workers. Interactions were scored after the $P$. conradti worker calmed down and no longer walked around, whereas in all other tests described in the following section, aggression scoring was recorded starting $10 \mathrm{~s}$ after introduction of an intruder into the arena.

Aggression of $S$. maynei towards workers of alien $S$. maynei colonies was tested by introducing a $S$. maynei individual in an arena (diameter $8 \mathrm{~cm}$ ) with $40 \mathrm{~S}$. maynei workers from nest $\mathrm{N}_{1}, \mathrm{~N}_{2}$ or $\mathrm{N}_{3}$. The introduced $S$. maynei individuals belonged to one of these colonies, but tests were performed blind with respect to the origin of these workers. Aggression tests with $S$. maynei as defender were observed under a Leica MZ6 stereo-microscope.

The effect of nest origin, i.e. same nest or alien nest, of an introduced S. maynei worker on the proportion of aggressive interactions elicited in an arena with $40 \mathrm{~S}$. maynei workers were analyzed using a generalized linear mixed model (GLMM) with a binomial error distribution using R package lme4. Significance was tested using a likelihood ratio test using R package car. The nest origin of the introduced worker was included as a fixed factor, whereas the nine possible combinations of host and introducer colony (nest of host colonynest of introducer colony: $\mathrm{N}_{1}-\mathrm{N}_{1}, \mathrm{~N}_{1}-\mathrm{N}_{2}, \mathrm{~N}_{1}-\mathrm{N}_{3}, \mathrm{~N}_{2}-\mathrm{N}_{1}, \mathrm{~N}_{2}-$ $\mathrm{N}_{2}, \mathrm{~N}_{2}-\mathrm{N}_{3}, \mathrm{~N}_{3}-\mathrm{N}_{1}, \mathrm{~N}_{3}-\mathrm{N}_{2}$ and $\mathrm{N}_{3}-\mathrm{N}_{3}$ ) were included as a random intercept. In addition, an observation-level random intercept was incorporated to account for possible overdispersion (Browne et al. 2005). A similar model was run to assess the effect of nest origin of an introduced $P$. conradti worker on the proportion of aggressive interactions elicited in an arena with three $S$. maynei workers. As the two ant species originated from only two nests, the random factor that implemented the combination of acceptor and introducer colony had only four levels (nest of host colony-nest of introducer colony: $\mathrm{N}_{1}-\mathrm{N}_{1}$, $\mathrm{N}_{1}-\mathrm{N}_{3}, \mathrm{~N}_{3}-\mathrm{N}_{1}$ and $\mathrm{N}_{3}-\mathrm{N}_{3}$ ). Aggression of $P$. conradti towards other $P$. conradti workers and towards $S$. maynei, either from
Table 1 Overview of the aggression experiments

\begin{tabular}{|c|c|c|c|c|}
\hline Intruder & $\begin{array}{l}\text { Nest origin } \\
\text { intruder }\end{array}$ & Host & $\begin{array}{l}\text { Host workers } \\
\text { in arena }(N)\end{array}$ & Arena diameter \\
\hline \multicolumn{5}{|l|}{ Ants } \\
\hline P. conradti & Same nest & P. conradti & 1 & $8 \mathrm{~cm}$ \\
\hline P. conradti & Alien nest & P. conradti & 1 & $8 \mathrm{~cm}$ \\
\hline S. maynei & Same nest & P. conradti & 10 & $8 \mathrm{~cm}$ \\
\hline S. maynei & Alien nest & P. conradti & 10 & $8 \mathrm{~cm}$ \\
\hline P. conradti & Same nest & S. maynei & 3 & $3 \mathrm{~cm}$ \\
\hline P. conradti & Alien nest & S. maynei & 3 & $3 \mathrm{~cm}$ \\
\hline S. maynei & Same nest & S. maynei & 40 & $8 \mathrm{~cm}$ \\
\hline S. maynei & Alien nest & S. maynei & 40 & $8 \mathrm{~cm}$ \\
\hline \multicolumn{5}{|l|}{ Alien ants } \\
\hline 5 species & Extranidal & P. conradti & 10 & $8 \mathrm{~cm}$ \\
\hline 5 species & Extranidal & S. maynei & 40 & $8 \mathrm{~cm}$ \\
\hline \multicolumn{5}{|c|}{ Myrmecophiles } \\
\hline 6 species & Same nest & P. conradti & 10 & $8 \mathrm{~cm}$ \\
\hline 6 species & Same nest & S. maynei & 40 & $8 \mathrm{~cm}$ \\
\hline
\end{tabular}


the same or an alien nest, was not modelled as no variation was observed within a treatment.

The number of trials for each interaction is listed in Table 2.

\section{Cuticular hydrocarbon profiles of the ant partners}

Cuticular compounds of freeze-killed S. maynei workers (five samples from nest $\mathrm{N}_{4}$, three samples from nest $\mathrm{N}_{5}$ ) were extracted in $30 \mu \mathrm{L}$ of hexane (HPLC, Sigma-Aldrich) in 2-mL glass vials with PTFE septum (Sigma-Aldrich) for $10 \mathrm{~min}$. Because of their small size, five $S$. maynei workers were pooled per sample. The large $P$. conradti workers (five samples from each of nests $\mathrm{N}_{4}, \mathrm{~N}_{5}$ and $\mathrm{N}_{6}$ ) were extracted in $200 \mu \mathrm{L}$ of hexane for $10 \mathrm{~min}$. The samples of the $S$. maynei colony from $\mathrm{N}_{6}$ were contaminated, and only the $P$. conradti colony of that nest was therefore analyzed. Samples were evaporated at room temperature to dryness and stored at $-18{ }^{\circ} \mathrm{C}$. Prior to analysis, S. maynei samples were diluted again in $30 \mu \mathrm{L}$ hexane and $P$. conradti samples in $200 \mu \mathrm{L}$ hexane, and $2 \mu \mathrm{L}$ of these solutions were injected into a $\mathrm{GC} /$ MS (Thermo Fisher: TRACE 1300 gas chromatograph, ISQ series mass spectrometer) equipped with a Restek Rxi-5Sil MS column $(20 \mathrm{~m} \times 0.18 \mathrm{~mm} \times 0.18 \mu \mathrm{m})$. The method had an initial temperature profile consisting of $1 \mathrm{~min}$ at $40^{\circ} \mathrm{C}$, two temperature ramps from 40 to $200{ }^{\circ} \mathrm{C}$ at $20^{\circ} \mathrm{C} \mathrm{min}^{-1}$ and from 200 to $340^{\circ} \mathrm{C}$ at $8^{\circ} \mathrm{C} \mathrm{min}^{-1}$, after which the final temperature of $340^{\circ} \mathrm{C}$ was held for $4 \mathrm{~min}$. We used helium as a carrier gas at a flow rate of $0.9 \mathrm{~mL} \mathrm{~min}^{-1}$, splitless injection and an inlet temperature of $290{ }^{\circ} \mathrm{C}$. All samples and a linear $\mathrm{C} 7$ to $\mathrm{C} 40$ linear alkane ladder standard (49452-U, Supelco) at a concentration of 0.001 and $0.01 \mu \mathrm{g} / \mathrm{mL}$ were run in the same batch. Retention indices were calculated using cubic spline interpolation based on the elution times of the external alkane ladder standard. These calculations were done using an in-house developed R script (available from the authors on request).

For both ant species, we calculated the mean relative percentage of every compound and selected the compounds that had a higher relative percentage than $0.1 \%$ on average. These compounds were present in all individual samples of either $S$. maynei or P. conradti, even though some compounds composed less than $0.1 \%$ of the individual cuticular profile. Peaks were identified on the basis of their retention index and mass spectra. The analysis of the level of similarity among cuticular profiles was based on the hydrocarbon peaks that were shared by both ants to avoid the effect of shared absences. It is generally assumed that hydrocarbons are pivotal in nestmate recognition in ants (van Zweden and D'Ettorre 2010). The areas of the hydrocarbon peaks were first transformed by the

Table 2 Mean proportion of aggressive interactions of S. maynei and P. conradti towards inhabitants of the same or alien nests

\begin{tabular}{|c|c|c|c|c|c|}
\hline Introduced species & & $N$ & Platythyrea conradti & $N$ & Strumigenys maynei \\
\hline \multicolumn{6}{|l|}{ Ants } \\
\hline Platythyrea conradti same nest & & 20 & 0.00 & 30 & $0.07[0.05-0.10]$ \\
\hline Platythyrea conradti alien nest & & 15 & 1.00 & 30 & $0.05[0.03-0.08]$ \\
\hline Strumigenys maynei same nest & & 20 & 0.00 & 18 & $0.02[0.01-0.05]$ \\
\hline Strumigenys maynei alien nest & & 20 & 0.00 & 36 & $0.42[0.26-0.59]$ \\
\hline \multicolumn{6}{|l|}{ Alien ants } \\
\hline Monomorium pharaonis & & 10 & 0.00 & 5 & $0.91[0.82-0.97]$ \\
\hline Monomorium bicolor & & 10 & $0.03[0.01-0.06]$ & 5 & $0.91[0.82-0.97]$ \\
\hline Crematogaster sp. 1 & & 10 & $0.01[0.00-0.03]$ & 4 & $0.90[0.79-0.96]$ \\
\hline Crematogaster sp. 2 & & 10 & $0.02[0.00-0.04]$ & 5 & $0.98[0.92-1.00]$ \\
\hline Oecophylla longinoda & & 10 & $0.08[0.04-0.13]$ & 5 & $0.90[0.81-0.96]$ \\
\hline \multicolumn{6}{|l|}{ Myrmecophiles } \\
\hline \multicolumn{6}{|l|}{ Coleoptera } \\
\hline Pselaphinae sp. 1 & Subtribe Batrisina & 9 & $0.01[0.00-0.05]$ & 7 & $0.58[0.49-0.66]$ \\
\hline Scydmaeninae sp. & "Napoconnus complex" of genera & 5 & 0.00 & 5 & $0.42[0.32-0.52]$ \\
\hline Holotrochus sp. & Staphylinidae: Osoriinae & 8 & 0.00 & 5 & $0.56[0.46-0.66]$ \\
\hline \multicolumn{6}{|l|}{ Collembola } \\
\hline Cyphoderus subsimilis & Cyphoderidae & 5 & 0.00 & 5 & $0.45[0.35-0.55]$ \\
\hline \multicolumn{6}{|l|}{ Thysanura } \\
\hline Neoasterolepisma delamarei & Lepismatidae & 9 & $0.25[0.15-0.37]$ & 4 & $0.83[0.73-0.90]$ \\
\hline Mesonychographis myrmecophila & Nicoletiidae: Atelurinae & 3 & 0.00 & - & - \\
\hline
\end{tabular}

Ninety-five percent confidence intervals in brackets

$N$ number of trials 
Aitchison's log-ratio transformation (Aitchison 1986), and samples were then grouped by a hierarchical cluster analysis (Euclidean distances, Ward's method) using the R function hclust. Finally, we examined which compounds were likely to be environmentally (i.e. shared by the two parabiotic ant species within a nest but not across nests) or genetically (i.e. shared by the same species across nests but not between species) determined. Therefore, we conducted a permutational multivariate analysis of variance using distance matrices (adonis function of the $\mathrm{R}$ package vegan, 1000 permutations). The factors "species" and "nest" and their interaction were modelled as explaining factors and a distance matrix with the Euclidean distances among the chemical profiles (Aitchison's transformed hydrocarbon dataset) of the parabiotic ants as response. As we did not have cuticular hydrocarbon (CHC) samples of $S$. maynei collected in $\mathrm{N}_{6}$, we dropped the five $P$. conradti samples of this nest from the dataset to have a fully crossed design ( $P$. conradti and $S$. maynei samples from $\mathrm{N}_{4}$ and $\mathrm{N}_{5}$ ).

\section{Potential benefits of the association}

A diverse group of myrmecophiles was collected in the 10 inspected nests (Online Resource, Table S1). It is unknown whether they are strictly associated with ants ("obligate myrmecophiles") or can be found in absence of ants as well ("facultative myrmecophiles"). However, three species, i.e. the springtail Cyphoderus subsimilis and the silverfish Neoasterolepisma delamarei and Mesonychographis myrmecophila, are expected to be obligate myrmecophiles, based on previous records with ants and/or a strict myrmecophile relationship of related taxa (Table S1). Many myrmecophiles impose costs on their host by preying on their brood or by feeding on prey brought to the nest (Kronauer and Pierce 2011; Parmentier et al. 2016). Similarly, most myrmecophiles in the parabiotic nest are expected to impose costs on the parabiotic hosts. Therefore, an efficient defense strategy against these intruders could be beneficial for both parabiotic ant partners. Here, we tested whether one ant partner was more efficient in detecting and attacking these intruders. Aggression of $P$. conradti and $S$. maynei was tested towards six myrmecophiles that were common in the nests (Table S1): Pselaphinae sp. 1 (Coleoptera), Scydmaeninae sp. (Coleoptera), Holotrochus sp. (Coleoptera, Staphylinidae), Cyphoderus subsimilis (Collembola), Neoasterolepisma delamarei (Thysanura) and Mesonychographis myrmecophila (Thysanura). Except for the springtail Cyphoderus subsimilis, they are expected to impose costs on their host. In addition to intranidal enemies, ant nests can be attacked by extranidal enemies. The most important enemies of ants are other ants (Hölldobler and Wilson 1990). Therefore, aggression of both parabiotic ants was also tested towards five ant species, which were very common in the study area. Ant species were selected along a size gradient (from small to large: Monomorium pharaonis, Monomorium bicolor, Crematogaster sp. 1, Crematogaster sp. 2, Oecophylla longinoda) to assess whether the relative size of the ant enemy affected aggression of $P$. conradti or S. maynei. Aggression tests of $P$. conradti and S. maynei towards myrmecophiles and alien ants (Table 1) were conducted similarly as described in the previous aggression trials. Myrmecophiles were introduced in an arena (diameter $8 \mathrm{~cm}$ ) with 10 workers of $P$. conradti found in the same nest (nests $\mathrm{N}_{2}, \mathrm{~N}_{3}, \mathrm{~N}_{6}, \mathrm{~N}_{7}$ and $\mathrm{N}_{8}$ ); workers of alien ant species were introduced in an arena (diameter $8 \mathrm{~cm}$ ) with $10 P$. conradti workers of nest $\mathrm{N}_{5}$. Aggression of $S$. maynei towards myrmecophiles and alien ant workers was tested in the same way, but observations were done under a Leica MZ6 stereo-microscope. Myrmecophiles here were introduced in test arenas with 40 S. maynei workers collected in the same nest (nests $\mathrm{N}_{3}, \mathrm{~N}_{5}$ and $\mathrm{N}_{6}$ ); alien ants were introduced in an arena with $40 \mathrm{~S}$. maynei workers of nest $\mathrm{N}_{5}$. Different myrmecophile and alien ant individuals were used per trial. To assess the confidence intervals listed under alien ants and myrmecophiles in Table 2, we ran four different quasibinomial generalized linear models. In particular, the proportion of aggression of $S$. maynei towards alien ants (model 1) and myrmecophiles (model 2) and the proportion of aggression of $P$. conradti towards alien ants (model 3) and towards myrmecophiles (model 4) were modelled as response variable and species as explaining factor.

\section{Results}

\section{The nature and specificity of the association}

Colonies of P. conradti and S. maynei were always found together in the 10 inspected branches. Brood of both species was present in most of the inspected nests but was clearly separated. The ten colonies of $S$. maynei were all polygynous and contained multiple breeding queens, and winged male and female sexuals were also recorded (Fig. 1d). In one P. conradti colony, male sexuals were observed. P. conradti did not show any aggression towards workers of $S$. maynei living in the same compound nest or coming from an alien nest (Table 2, Online Resource video S1). In contrast, alien $P$. conradti workers were directly and fiercely attacked by biting and stinging (Fig. 1c). The workers involved in the fight could not be separated and fought until death. Therefore, the proportion of aggressive interactions in Table 2 was set to one. Like P. conradti, S. maynei was very aggressive towards conspecific workers of an alien nest (GLMM, likelihood ratio test, $d f=1, \chi^{2}=32.56, P<0.001$ ) (Fig. 1b).

$S$. maynei showed limited aggression towards $P$. conradti living in the same nest, and aggression was not elevated when P. conradti originated from an alien nest (GLMM, likelihood ratio test, $d f=1, \chi^{2}=1.33, P=0.248$ ) (Table 2, Online Resource S1). A power analysis for this mixed model was 
performed using the $\mathrm{R}$ package simr. It showed that an increase in the proportion of aggressive interactions from 0.07 (aggression of $S$. maynei against $P$. conradti nestmates) to $0.17,0.27,0.37$ and 0.47 could be detected with a power of, respectively, 17.1, 42.9, 69.8 and $90.0 \%$. This implies that a small increase in aggression is unlikely to be detected with our setup. However, we showed that $S$. maynei strongly elevates its aggression towards alien $S$. maynei workers compared to workers of its own colony. When $S$. maynei would be able to recognize its $P$. conradti nest partner, a similar large increase in aggression could be expected towards alien P. conradti. This expectation is in line with the findings of a previous study (Orivel and Dejean 1997). Here, it was shown that parabiotic ants, which are able to recognize the partner colony, dramatically increased aggression towards alien partners.

S. maynei was never observed soliciting for food, and grooming behavior between heterospecific workers was also absent. No interspecific brood predation was observed between the ant partners in lab nests.

\section{Cuticular hydrocarbon profiles of the ant partners}

A total of 78 different peaks were distinguished across both ant species. The majority of the peaks consisted of linear hydrocarbons $(N=59)$ (Table 3$)$, which could be identified based on their mass spectra and retention indices. There were also nonhydrocarbon compounds which we did not identify $(N=19)$. The profile of $P$. conradti was distinct from that of $S$. maynei, with a much higher proportion of light hydrocarbons (between n-C21 and n-C27) (Table 3, Fig. 3). Nevertheless, both species shared 30 hydrocarbon peaks (Table 3, Fig. 3). The summed concentrations of these 30 hydrocarbons contributed to $91 \%$ of the total CHC concentration in S. maynei and $89 \%$ in $P$. conradti and represent, thus, the majority of the nestmate recognition cues. P. conradti and S. maynei formed two distinct clusters in the hierarchical cluster analysis and the workers grouped per nest within both clusters (Fig. 4). This was confirmed by the multivariate permutation test which showed a very strong (explained $78.8 \%$ of the total $\mathrm{CHC}$ variation across samples) species effect on hydrocarbon composition $(\mathrm{F}=110.50, P<0.001)$. There were also small effects of the nest environment (explained 5.8\% of the total $\mathrm{CHC}$ variation across samples) $(F=8.19, P=0.02)$ and the interaction effect (explained $5.4 \%$ of the total variation, $F=7.53, P=0.01$ ) on an individual's $\mathrm{CHC}$ composition. However, these results are based on merely two nests, and a larger dataset should be needed to assess more precisely how the common nest environment affects the hydrocarbon profile of the parabiotic ants.

\section{Potential benefits of the association}

Myrmecophiles and alien ants elicited no or only limited aggression in P. conradti (Table 2). Surprisingly, P. conradti avoided alien ants and regularly tried to escape even when the introduced workers were much smaller (Online Resource videos 2, 3). This can be seen for the total number of escapes out of total number of interactions in trials with: Monomorium bicolor $N=8 / 200$, Crematogaster sp. $1 N=8 / 200$, Crematogaster sp. $2 N=20 / 200$ and $O$. longinoda $N=8 /$ 200. P. conradti seldom initiated a fight with an alien ant and showed in general merely aggression when it was bitten or stung by the introduced alien ant worker. Alien ants and myrmecophiles evoked a strong aggression response in S. maynei, in clear contrast to what we observed in P. conradti. S. maynei workers typically grabbed the legs of the intruder and tried to sting (Online Resource: videos 4, 5, 6, 7 and 8). An overview of the tested interactions between the inhabitants of the compound nests is schematically illustrated in Fig. 2.

We observed S. maynei with small prey collected from the organic nest material (three times with Collembola: Cyphoderus subsimilis, twice with Pseudoscorpiones) held between their mandibles in lab nests.

\section{Discussion}

In this study, we identified a unique association between two Afrotropical ants. Colonies of the tiny ant Strumigenys maynei and the large ant Platythyrea conradti lived together in all inspected tree nests in the study area. There was little or no aggression between the two partners, but there were also no signs of intimate heterospecific interactions such as trophallaxis or grooming which are observed between ants and specialized myrmecophiles or social parasites (Hölldobler and Wilson 1990; Buschinger 2009). Because of the strict association and the lack of aggression between the two partners, this association can be considered as a parabiosis.

Our results confirmed that parabiotic partners might associate with each other despite having distinct nestmate recognition cues (Orivel and Dejean 1997; Menzel et al. 2008a; Menzel et al. 2009; Emery and Tsutsui 2013) (Figs. 3 and 4). Previous studies showed that parabiotic partners hardly shared any cuticular compounds (summarized in Table 1 in Emery and Tsutsui 2013). P. conradti and S. maynei, in contrast, had $51 \%$ of hydrocarbons in common. CHC composition was slightly affected by the nest environment (e.g. by passive transfer between the parabiotic partners, nest material, diet...), but the cuticular cues of an individual were mainly determined by species identity ("genetic"). It is unclear, however, whether the parabiotic lifestyle of the ants of this study exerts selection on the presence and proportional composition of nestmate recognition cues (cf. Menzel et al. 2013) to facilitate the recognition and/or acceptance in the association. The ants clearly perceive conspecific workers with a slightly different chemical profile in both species as they showed strong aggression against conspecific workers. Tolerance of the 
Table 3 Comparison of cuticular components (average percentages $\pm \mathrm{SD})$ of $S$. maynei $\left(N_{\text {pooled }}=9\right)$ and $P$. conradti $(N=15)$

\begin{tabular}{|c|c|c|c|c|c|c|c|c|c|}
\hline Peak no. & Retention index & & S. maynei & P. conradti & Peak no. & $\begin{array}{l}\text { Retention } \\
\text { index }\end{array}$ & & S. maynei & P. conradti \\
\hline 1 & 2026.78 & Non-HC & $0.33 \pm 0.13$ & - & 40 & 2686.00 & Non-HC & $0.27 \pm 0.54$ & - \\
\hline 2 & 2053.23 & Non-HC & $0.50 \pm 0.54$ & - & 41 & 2686.73 & 4,16-diMeC26 & - & $1.41 \pm 0.71$ \\
\hline 3 & 2100.02 & n-C21 & $0.22 \pm 0.06$ & $0.32 \pm 0.25$ & 42 & 2699.59 & $\mathrm{n}-\mathrm{C} 27$ & $7.37 \pm 2.63$ & $4.56 \pm 1.98$ \\
\hline 4 & 2130.00 & Non-HC & $0.28 \pm 0.33$ & - & 43 & 2732.58 & 13,11,9-MeC27 & $3.00 \pm 1.96$ & $8.45 \pm 2.48$ \\
\hline 5 & 2149.00 & Non-HC & $8.56 \pm 13.68$ & - & 44 & 2750.09 & 5-MeC27 & $0.21 \pm 0.11$ & $0.52 \pm 0.15$ \\
\hline 6 & 2172.96 & 3-MeC21 & - & $0.67 \pm 0.71$ & 45 & 2760.52 & Non-HC & $6.51 \pm 14.07$ & $0.41 \pm 0.44$ \\
\hline 7 & 2199.84 & $\mathrm{n}-\mathrm{C} 22$ & $0.22 \pm 0.11$ & $0.18 \pm 0.12$ & 46 & 2773.96 & 3-MeC27 & $8.74 \pm 2.90$ & $4.98 \pm 1.57$ \\
\hline 8 & 2276.74 & $\mathrm{C} 23: 1$ & - & $0.25 \pm 0.27$ & 47 & 2781.75 & 5,y-diMeC27 & $0.66 \pm 0.19$ & $0.77 \pm 0.22$ \\
\hline 9 & 2299.58 & n-C23 & $0.34 \pm 0.17$ & $2.94 \pm 1.16$ & 48 & 2799.17 & n-C28 & $1.15 \pm 0.36$ & $0.13 \pm 0.09$ \\
\hline 10 & 2303.00 & Non-HC & $0.48 \pm 0.34$ & - & 49 & 2806.40 & 3,y-diMeC27 & $2.23 \pm 1.42$ & $1.90 \pm 0.54$ \\
\hline 11 & 2335.71 & 11,9-MeC23 & - & $1.68 \pm 0.50$ & 50 & 2831.48 & 12-MeC28 & - & $0.38 \pm 0.08$ \\
\hline 12 & 2341.78 & 7-MeC23 & - & $0.31 \pm 0.22$ & 51 & 2832.00 & Non-HC & $0.68 \pm 0.21$ & - \\
\hline 13 & 2350.62 & 5-MeC23 & - & $0.45 \pm 0.17$ & 52 & 2839.97 & Non-HC & $0.58 \pm 0.42$ & $0.45 \pm 0.25$ \\
\hline 14 & 2373.01 & 3-MeC23 & - & $2.33 \pm 1.58$ & 53 & 2850.61 & Non-HC & $10.88 \pm 10.60$ & $0.82 \pm 0.39$ \\
\hline 15 & 2377.00 & Non-HC & $0.14 \pm 0.09$ & - & 54 & 2862.00 & 4-MeC28 & $1.58 \pm 0.46$ & - \\
\hline 16 & 2398.00 & Non-HC & $0.56 \pm 0.36$ & - & 55 & 2869.00 & Non-HC & $1.13 \pm 0.62$ & - \\
\hline 17 & 2399.56 & $\mathrm{n}-\mathrm{C} 24$ & - & $0.56 \pm 0.27$ & 56 & 2869.84 & $\mathrm{x}-\mathrm{C} 29: 1$ & - & $0.64 \pm 0.31$ \\
\hline 18 & 2408.97 & 3,13-diMeC23 & - & $0.71 \pm 1.24$ & 57 & 2879.34 & $\mathrm{y}-\mathrm{C} 29: 1$ & $0.74 \pm 0.47$ & $1.65 \pm 0.81$ \\
\hline 19 & 2415.00 & Non-HC & $0.14 \pm 0.06$ & - & 58 & 2888.87 & Non-HC & - & $0.15 \pm 0.06$ \\
\hline 20 & 2434.72 & x-MeC24 & $0.17 \pm 0.03$ & $1.11 \pm 0.30$ & 59 & 2899.04 & n-C29 & $4.73 \pm 1.80$ & $0.27 \pm 0.14$ \\
\hline 21 & 2445.26 & 6-MeC24 & - & $0.25 \pm 0.13$ & 60 & 2930.37 & 15,13,11,9-МeC29 & $2.19 \pm 0.72$ & $0.93 \pm 0.28$ \\
\hline 22 & 2458.02 & 4-MeC24 & - & $0.21 \pm 0.17$ & 61 & 2940.00 & 7-MeC29 & $0.25 \pm 0.20$ & - \\
\hline 23 & 2477.21 & $\mathrm{x}-\mathrm{C} 25: 1$ & - & $1.88 \pm 0.77$ & 62 & 2950.00 & 5-MeC29 & $0.40 \pm 0.22$ & - \\
\hline 24 & 2484.73 & $\mathrm{y}-\mathrm{C} 25: 1$ & - & $0.46 \pm 0.21$ & 63 & 2962.05 & x,y-diMeC29 & $1.31 \pm 0.55$ & $0.13 \pm 0.05$ \\
\hline 25 & 2486.00 & Non-HC & $0.98 \pm 0.67$ & - & 64 & 2973.11 & 3-MeC29 & $4.28 \pm 1.14$ & $0.19 \pm 0.05$ \\
\hline 26 & 2492.54 & 4,14-diMeC24 & - & $0.21 \pm 0.13$ & 65 & 2980.09 & 5,y-diMeC29 & - & $0.10 \pm 0.03$ \\
\hline 27 & 2499.80 & n-C25 & $1.13 \pm 0.55$ & $5.36 \pm 2.64$ & 66 & 3000.00 & n-C30 & $0.17 \pm 0.07$ & - \\
\hline 28 & 2534.29 & 13,11,9-MeC25 & $0.68 \pm 0.88$ & $10.74 \pm 1.52$ & 67 & 3030.00 & x-MeC30 & $0.67 \pm 0.43$ & - \\
\hline 29 & 2541.89 & 7-MeC25 & $0.30 \pm 0.45$ & $2.01 \pm 1.32$ & 68 & 3052.34 & Non-HC & - & $0.14 \pm 0.09$ \\
\hline 30 & 2550.63 & 5-MeC25 & - & $1.04 \pm 0.44$ & 69 & 3056.00 & Non-HC & $1.07 \pm 0.45$ & - \\
\hline 31 & 2573.83 & 3-MeC25 & $1.58 \pm 0.82$ & $7.58 \pm 2.10$ & 70 & 3069.92 & C31:1 & $0.18 \pm 0.09$ & $0.31 \pm 0.21$ \\
\hline 32 & 2582.63 & 5,y-diMeC25 & $0.27 \pm 0.23$ & $1.56 \pm 0.64$ & 71 & 3080.70 & C31:1 & $0.15 \pm 0.09$ & $0.23 \pm 0.19$ \\
\hline 33 & 2599.71 & $\mathrm{n}-\mathrm{C} 26$ & $0.45 \pm 0.25$ & $1.19 \pm 0.49$ & 72 & 3100.00 & n-C31 & $0.94 \pm 0.77$ & - \\
\hline 34 & 2607.99 & 3,y-diMeC25 & $0.72 \pm 0.46$ & $3.42 \pm 1.91$ & 73 & 3129.40 & 15,13,11,9-MeC31 & $2.27 \pm 1.54$ & $0.62 \pm 0.29$ \\
\hline 35 & 2633.19 & x-MeC26 & $0.23 \pm 0.22$ & $2.64 \pm 0.40$ & 74 & 3178.38 & Non-HC & $10.77 \pm 5.32$ & $1.94 \pm 1.49$ \\
\hline 36 & 2644.41 & 6-MeC26 & - & $0.25 \pm 0.09$ & 75 & 3228.00 & Non-HC & $1.11 \pm 0.70$ & - \\
\hline 37 & 2657.98 & 4-MeC26 & - & $0.44 \pm 0.21$ & 76 & 3300.00 & n-C33 & $0.21 \pm 0.09$ & - \\
\hline 38 & 2662.00 & Unknown HC & $0.64 \pm 0.42$ & - & 77 & 3328.47 & x-MeC33 & $1.34 \pm 0.81$ & $0.22 \pm 0.10$ \\
\hline 39 & 2678.57 & C27:1 & $2.14 \pm 5.07$ & $16.81 \pm 4.49$ & 78 & 3527.26 & $\mathrm{x}-\mathrm{MeC} 35$ & $1.17 \pm 0.44$ & $0.13 \pm 0.08$ \\
\hline
\end{tabular}

$H C$ hydrocarbon, Non-HC non-hydrocarbon component

parabiotic species can be limited to a single heterospecific partner colony. In this case, there is no aggression between parabiotic partners of the same nest, but both species are aggressive towards allocolonial (=from another compound nest) workers of their partner species (Orivel and Dejean 1997; Emery and Tsutsui 2013). It is suggested that the partners learn to recognize the distinct chemical odor of their partner colony (Orivel and Dejean 1997). Other associations are less specific and are characterized by complete or a gradient of tolerance towards allocolonial workers from the partner species (Menzel et al. 2008b). The association between S. maynei and $P$. conradti is also not specific, as there is no elevated 


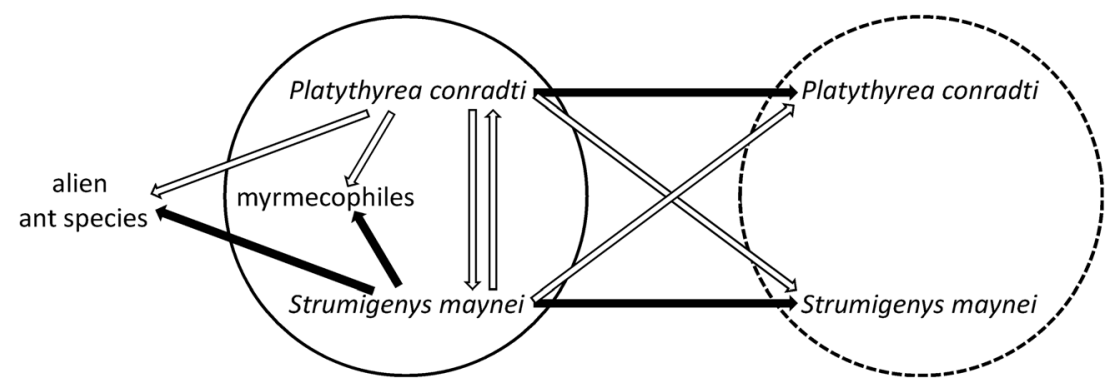

Fig. 2 Schematic overview of aggressive interactions in Platythyrea conradti-Strumigenys maynei compound nests based on Table 2. The solid circle symbolizes the focal nest and the dashed circle an alien nest. Arrows refer to an interaction between $P$. conradti or S. maynei

aggression towards allocolonial workers of the partner. Both species apparently accept all colonies from the partner species. This can be explained by the recognition of species-specific rather than colony-specific chemical cues or the detection of appeasing cues (Menzel et al. 2013). However, the tolerance of the parabiotic partner might also be caused by a merely mechanistic process. Possibly $S$. maynei is too small to be detected efficiently by $P$. conradti. However, it was reported that $P$. conradti detected $S$. maynei when it fed on its prey and carried them away (Yéo et al. 2006). On the other hand, P. conradti workers might be too large to be attacked by $S$. maynei colonies towards species at the end of the arrow. White arrows indicate no or minimal aggression, whereas black arrows designate overt aggression

workers. It should be noted here that they successfully attacked Paltothyreus tarsatus, an ant which equals the size of $P$. conradti (pers. observations TP).

Yéo et al. (2006) found two dealate inseminated queens of $S$. maynei in a small $P$. conradti colony. This suggests that $P$. conradti is the founder of the compound nest and that a $S$. maynei colony do not fission when its partner $P$. conradti colony splits. It appears rather that $S$. maynei queens track $P$. conradti soon after migration to a new nest site. Multiple $S$. maynei queens might found a new colony (primary polygyny) in the $P$. conradti nest, or new queens might be accepted in a well-established $S$. maynei colony (secondary polygyny).

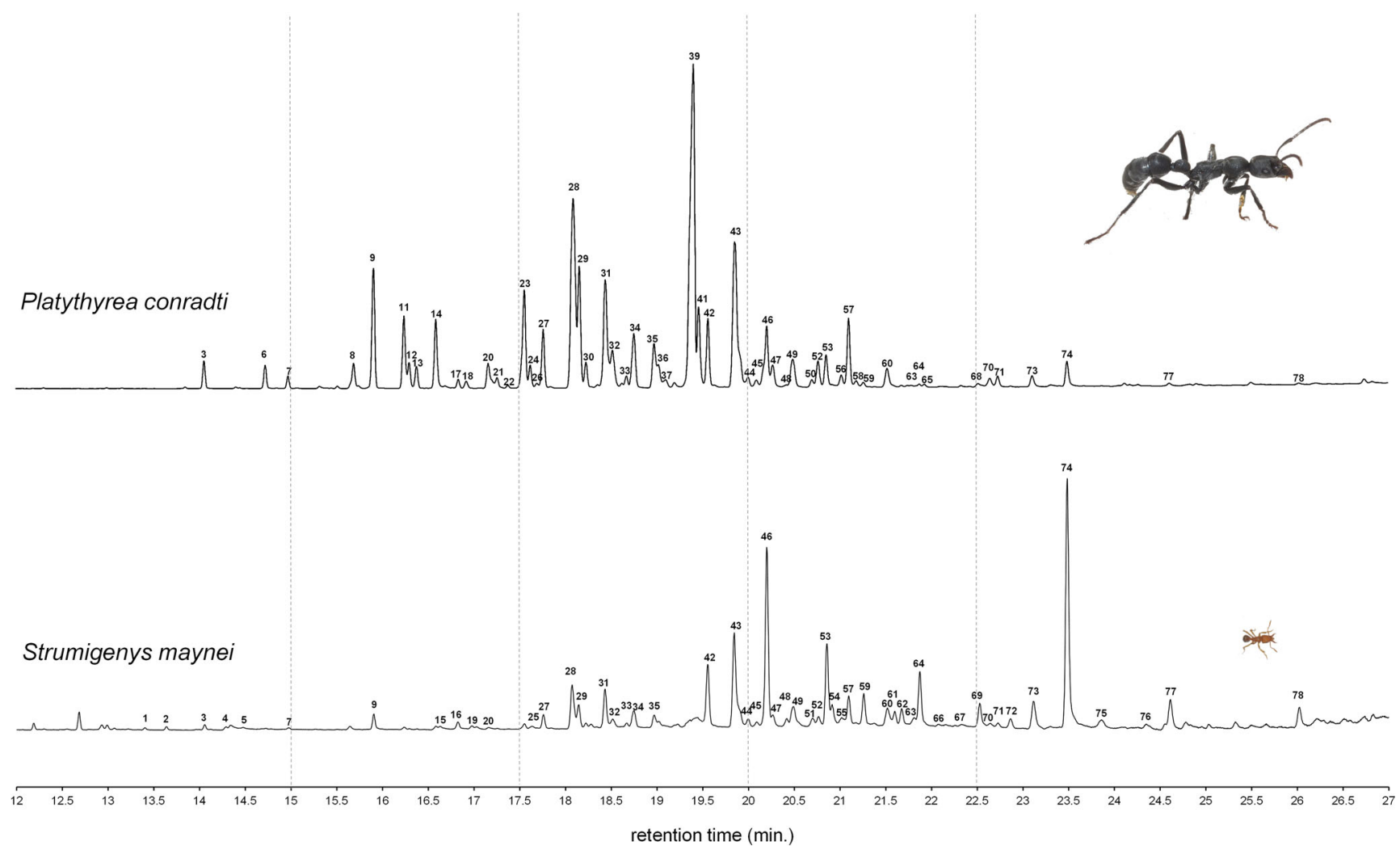

Fig. 3 Representative gas chromatograms of the two co-inhabiting ant species with the relative intensity of peaks in function of retention time. The identity of the peaks corresponding with the peak numbers is given in Table 3 


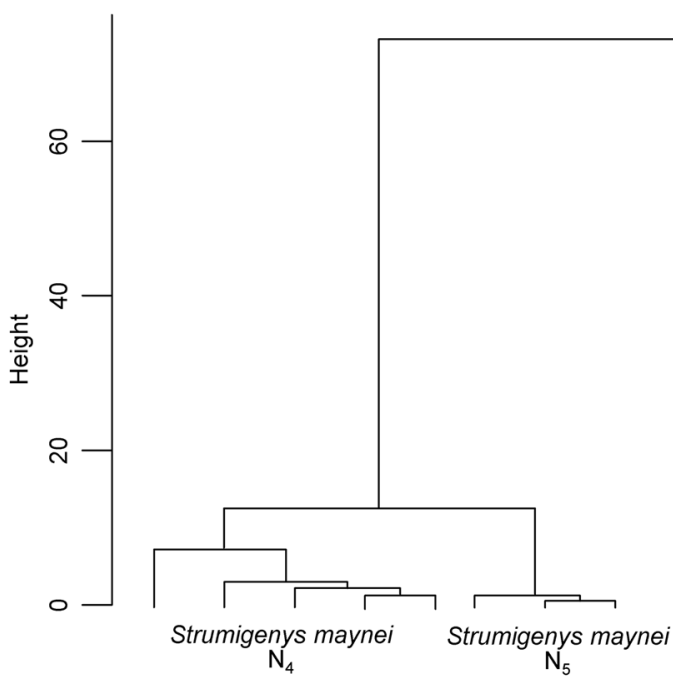

Fig. 4 Hierarchical cluster analysis of the shared cuticular hydrocarbons of Platythyrea conradti and Strumigenys maynei (Euclidean distance, Ward's method). Colonies of $S$. maynei and $P$. conradti were analyzed

Both ant species seem to benefit from the presence of the other partner. We argue that $P$. conradti takes advantage of $S$. maynei, because the latter is much more efficient in nest defending. Typical threats for ant nests are competitor ants that may rob and destroy the colony and associated myrmecophiles that can prey on the brood and steal prey (Hölldobler and Wilson 1990; Parmentier et al. 2016). Remarkably, the large P. conradti workers ignored all myrmecophiles, except for $N$. delamarei. Probably, the relative large size of the latter compared with the other myrmecophiles renders them more detectable for $P$. conradti. P. conradti also ignored competitor ants, irrespective of their size, or even tried to escape. Fights were never initiated by this ant, and aggressive behavior was only observed after it was attacked. In a previous study, it was described that these ants crouched with their mandibles open and folded their antennae backwards when they were confronted with competitor ants at a feeding site (Dejean 2011). It was hypothesized that $P$. conradti opened its mandibles to release repellent volatiles secreted by the mandibular glands (Dejean 2011). This peculiar crouching behavior was also observed in our behavioral trials but rarely in combination with mandible opening. In clear contrast, S. maynei displayed overt aggression towards myrmecophiles and towards alien ants, irrespective of their size. They typically clung to the legs of the enemies and folded their abdomen to sting. It can be expected that the rather passive $P$. conradti colonies highly benefit from the presence of a large legion of very aggressive $S$. maynei workers. The presented association is peculiar because of the large size differences between the two partners. The large worker force of tiny S. maynei ants is particularly efficient to repel small intruders and competitors, which are largely overlooked by the large $P$. conradti workers. By analogy, small workers in polymorphic red wood ants were demonstrated to be supreme defenders against small, intranidal myrmecophilous parasites (Parmentier et al. 2015). The large $P$. conradti workers might be more suited to repel large arthropods or vertebrates in parallel with the defense specialization of large workers in polymorphic ant colonies against large enemies (Lamon and Topoff 1981; Hölldobler and Wilson 1990; Batchelor et al. 2012). There is a vast amount of literature that stresses the specialization of morphologically distinct worker castes in nest defense (Jandt et al. 2013; Tian and Zhou 2014), but here, we argue that morphologically distinct ant species can be analogously specialized in different tasks. These distinct morphs in the compound nest could be an alternative strategy for worker polymorphism in a single colony of an ant species. Worker polymorphism is assumed to benefit colony fitness as some worker castes are more efficient in the performance of certain tasks (Oster and Wilson 1978; Billick and Carter 2007; Modlmeier and Foitzik 2011; Jandt et al. 2013). Rather than diversifying the morphology of their own worker caste, ants might form a mutualistic association with a morphologically distinct ant species which is more efficient in certain tasks.

$S$. maynei colonies, in their turn, might also benefit from the parabiotic association. P. conradti workers fill the nest entrances with a plug of fine and coarse organic material (Fig. 1e) and as such create a microcosm for small arthropods. This can be demonstrated by the enormous abundance of mainly Collembola (Cyphoderus subsimilis) that were regularly detected inside the nests (Online Resource Video 9). The genus Strumigenys is a group of small predators that capture living prey with their odd-shaped mandibles (Bolton 1999). In this study and in Yéo et al.'s (2006), it was demonstrated that $S$. maynei captured intranidal prey. It appears that $S$. maynei indirectly profits from the nest engineering skills of $P$. conradti to feed on prey living inside the compound nest. Previously, it was observed that $P$. conradti hunted actively 
several arthropods in the tree canopy in the rainy season, whereas $S$. maynei workers never foraged further than $10 \mathrm{~cm}$ away from the nest entrances (Yéo et al. 2006). This further suggests that $S$. maynei finds its food inside the nest.

Given the apparent benefits for both partners in this parabiotic association and the absence of potential costs, i.e. no food competition and brood predation, this parabiosis is expected to be mutualistic in nature. This is in line with previous studies on parabioses in the Neotropical and Oriental associations between Camponotus and Crematogaster species which gave evidence that the association was favorable for both parabiotic partners. Crematogaster takes advantage of Camponotus's ability to construct ant garden nests and its supreme nest defending abilities (Davidson 1988; Vantaux et al. 2007; Menzel and Blüthgen 2010). Camponotus benefits from Crematogaster through following its pheromone trails to food sites (Vantaux et al. 2007; Menzel and Blüthgen 2010). However, parabioses between Camponotus and Crematogaster can also shift to commensalism and parasitism, when there is aggressive competition, exploitation and no apparent benefits for one partner (Menzel et al. 2014).

The parabiotic system of this study is an excellent model system to test interactions between symbiotic arthropods. Further behavioral, ecological and chemical studies that compare the strategies of S. maynei and P. conradti living in association compared to free-living colonies of both species could greatly contribute to our knowledge on the factors that promote the association and cooperation of two distinct species. Moreover, this study raises an interesting hypothesis that this proposed defense mutualism between size-polymorphic ant species is an adaptive alternative to the evolution of a defensive worker polymorphism within one species.

Acknowledgements This research was supported by a type II grant of the Belgian Focal Point of the Global taxonomy Initiative, by a grant from the FWO Vlaanderen (Research Foundation Flanders) to TP (grant nr. $11 \mathrm{D} 6414 \mathrm{~N})$ and by the Centre of Excellence grant PF/10/07-SEEDS. Field work and aggression experiments were done during the Ant and Bee course at Lamto. We would like to thank Sébastien Kouamé Kan Loukou, Nangounon Soro and Nanga Yeo for their assistance in the field and with their help in conducting preliminary experiments and Ricardo Caliari Oliveira for his assistance with the GCMS analysis. We are very grateful for the identification of the myrmecophile species by the following experts: Rafael Molero Baltanás (Thysanura), Frans Janssens (Collembola), Paweł Jałoszyński (Scydmaeninae), Volker Brachat (Pselaphinae) and Tim Struyve (Staphylinidae).

\section{References}

Aitchison J (1986) The statistical analysis of compositional data. Chapman and Hall, London

Batchelor TP, Santini G, Briffa M (2012) Size distribution and battles in wood ants: group resource-holding potential is the sum of the individual parts. Anim Behav 83:111-117. doi:10.1016/j.anbehav.2011. 10.014
Billick I, Carter C (2007) Testing the importance of the distribution of worker sizes to colony performance in the ant species Formica obscuripes Forel. Insect Soc 54:113-117. doi:10.1007/s00040007-0918-9

Bolton B (1999) Ant genera of the tribe Dacetonini (Hymenoptera: Formicidae). J Nat Hist 33:1639-1689

Bolton B (2000) The ant tribe Dacetini. Memoirs of the American Entomological Institute 65:1-1028

Browne WJ, Subramanian SV, Jones K, Goldstein H (2005) Variance partitioning in multilevel logistics models with over-dispersion. J R Stat Soc A 168:599-613

Buschinger A (2009) Social parasitism among ants: a review (Hymenoptera: Formicidae). Myrmecological News 12:219-235

Davidson DW (1988) Ecological studies of neotropical ant gardens. Ecology 69:1138-1152

Dejean A (2011) Prey capture behavior in an arboreal african ponerine ant. PLoS One 6:e19837. doi:10.1371/journal.pone.0019837

Dixson DL, Hay ME (2012) Corals chemically cue mutualistic fishes to remove competing seaweeds. Science 338:804-807. doi:10.1126/ science. 1225748

Emery VJ, Tsutsui ND (2013) Recognition in a social symbiosis: chemical phenotypes and nestmate recognition behaviors of neotropical parabiotic ants. PLoS One. doi:10.1371/journal.pone.0056492

Herre EA, Knowlton N, Mueller UG, Rehner SA (1999) The evolution of mutualisms: exploring the paths between conflict and cooperation. Trends Ecol Evol 14:49-53. doi:10.1016/S0169-5347(98)01529-8

Hölldobler B, Wilson EO (1990) The ants. Harvard University Press Cambridge, Massachusetts

Jandt JM, Bengston S, Pinter-wollman N et al (2013) Behavioural syndromes and social insects: personality at multiple levels. Biol Rev 89:48-67. doi:10.1111/brv.12042

Kronauer DJC, Pierce NE (2011) Myrmecophiles. Curr Biol 21:208-209. doi:10.1016/j.cub.2011.01.050

Lamon B, Topoff H (1981) Avoiding predation by army ants: defensive behaviours of three ant species of the genus Camponotus. Anim Behav 29:1070-1081. doi: 10.1016/S0003-3472(81)80060-7

Menzel F, Blüthgen N (2010) Parabiotic associations between tropical ants: equal partnership or parasitic exploitation? J Anim Ecol 79: 71-81. doi:10.1111/j.1365-2656.2009.01628.x

Menzel F, Schmitt T (2012) Tolerance requires the right smell: first evidence for interspecific selection on chemical recognition cues. Evolution 66:896-904. doi:10.1111/j.1558-5646.2011.01489.x

Menzel F, Blüthgen N, Schmitt T (2008a) Tropical parabiotic ants: highly unusual cuticular substances and low interspecific discrimination. Front Zool 5:16. doi:10.1186/1742-9994-5-16

Menzel F, Linsenmair KE, Blüthgen N (2008b) Selective interspecific tolerance in tropical Crematogaster-Camponotus associations. Anim Behav 75:837-846. doi:10.1016/j.anbehav.2007.07.005

Menzel F, Schmitt T, Blüthgen N (2009) Intraspecific nestmate recognition in two parabiotic ant species: acquired recognition cues and low inter-colony discrimination. Insect Soc 56:251-260. doi:10.1007/ s00040-009-0018-0

Menzel F, Blüthgen N, Tolasch T et al (2013) Crematoenones - a novel substance class exhibited by ants functions as appeasement signal. Front Zool 10:32. doi:10.1186/1742-9994-10-32

Menzel F, Kriesell H, Witte V (2014) Parabiotic ants: the costs and benefits of symbiosis. Ecol Entomol 39:436-444. doi:10.1111/een. 12116

Modlmeier AP, Foitzik S (2011) Productivity increases with variation in aggression among group members in Temnothorax ants. Behav Ecol 22:1026-1032. doi:10.1093/beheco/arr086

Molet M, Peeters C (2006) Evolution of wingless reproductives in ants: weakly specialized ergatoid queen instead of gamergates in Platythyrea conradti. Insect Soc 53:177-182. doi:10.1007/s00040005-0856-3 
Orivel J, Dejean A (1997) Ant gardens: interspecific recognition in parabiotic ant species. Behav Ecol Sociobiol 40:87-93. doi:10.1007/ s002650050319

Oster GF, Wilson EO (1978) Caste and ecology in the social insects. Princeton University Press, NJ. Princeton.

Parmentier T, Dekoninck W, Wenseleers T (2015) Context-dependent specialization in colony defence in the red wood ant Formica rufa. Anim Behav 103:161-167. doi:10.1016/j.anbehav.2015.02.023

Parmentier T, Bouillon S, Dekoninck W, Wenseleers T (2016) Trophic interactions in an ant nest microcosm: a combined experimental and stable isotope $(\delta 13 \mathrm{C} / \delta 15 \mathrm{~N})$ approach. Oikos 125:1182-1192. doi: 10.1111/oik.02991
Tian L, Zhou X (2014) The soldiers in societies: defense, regulation, and evolution. Int J Biol Sci 10:296-308. doi:10.7150/ijbs.6847

van Zweden JS, d'Ettorre P (2010) Nestmate recognition in social insects and the role of hydrocarbons. In: Blomquist GJ, Bagnères A-G (eds) Insect hydrocarbons: biology, biochemistry, and chemical ecology. Cambridge University Press, Cambridge, pp 222-243

Vantaux A, Dejean A, Dor A, Orivel J (2007) Parasitism versus mutualism in the ant-garden parabiosis between Camponotus femoratus and Crematogaster levior. Insect Soc 54:95-99. doi:10.1007/ s00040-007-0914-0

Yéo K, Molet M, Peeters C (2006) When David and Goliath share a home: compound nesting of Pyramica and Platythyrea ants. Insect Soc 53:435-438. doi:10.1007/s00040-005-0890-9 